\title{
The Mouse Homeobox Gene Gbx2 Is Required for the Development of Cholinergic Interneurons in the Striatum
}

\author{
Li Chen, Mallika Chatterjee, and James Y. H. Li \\ Department of Genetics and Developmental Biology, University of Connecticut Health Center, Farmington, Connecticut 06030-6403
}

\begin{abstract}
Mammalian forebrain cholinergic neurons are composed of local circuit neurons in the striatum and projection neurons in the basal forebrain. These neurons are known to arise from a common pool of progenitors that primarily resides in the medial ganglionic eminence (MGE). However, little is known about the genetic programs that differentiate these two types of cholinergic neurons. Using inducible genetic fate mapping, here we examined the developmental fate of cells that express the homeodomain transcription factor Gbx2 in the MGE. We show that the $G b \times 2$ lineage-derived cells that undergo tangential migration exclusively give rise to almost all cholinergic interneurons in the striatum, whereas those undergoing radial migration mainly produce noncholinergic neurons in the basal forebrain. Deletion of $G b x 2$ throughout the mouse embryo or specifically in the MGE results in abnormal distribution and significant reduction of cholinergic neurons in the striatum. We show that early-born (before embryonic day 12.5) cholinergic interneurons preferentially populate the lateral aspect of the striatum and mature earlier than late-born (after embryonic day 12.5) neurons, which normally reside in the medial part of the striatum. In the absence of $G b x 2$, early-born striatal cholinergic precursors display abnormal neurite outgrowth and increased complexity, and abnormally contribute to the medial part of the caudate-putamen, whereas late-born striatal cholinergic interneurons are mostly missing. Together, our data demonstrate that $G b \times 2$ is required for the development of striatal cholinergic interneurons, perhaps by regulating tangential migration of the striatal cholinergic precursors.
\end{abstract}

\section{Introduction}

The mammalian forebrain contains two main groups of cholinergic neurons, which differ in their location and connectivity. One group consists of local circuit neurons (interneurons), which are located in the striatum and receive synaptic input from midbrain dopaminergic neurons and GABAergic projection neurons in the striatum (Gerfen, 1992; Kaneko et al., 2000). The other group of cholinergic neurons is distributed in different nuclei in the so-called Ch1-4 areas in the basal forebrain (Mesulam et al., 1983). These cholinergic neurons are projection neurons and innervate cortical and subcortical structures (Mesulam et al., 1983). Although they share similar biochemical properties, these two types of forebrain cholinergic neurons have very different functions (Berger-Sweeney, 2003; Smythies, 2005; Pisani et al., 2007).

All forebrain cholinergic neurons are generated in the ventral telencephalon, including the medial ganglionic eminence (MGE) and preoptic area (POA) (Olsson et al., 1998; Marín et al., 2000). Cholinergic precursors from the MGE/POA undergo radial migration to form projection neurons in the basal forebrain,

Received July 19, 2010; accepted Aug. 10, 2010.

This work is supported by grants from the National Institutes of Health and the March of Dimes Foundation (J.Y.H.L.). We are grateful to Dr. Sandra Blaess and laboratory members for discussion and critical reading of this manuscript. We thank Dr. Kairong Li and Qiuxia Guo for their technical help. We thank Dr. Louise Reichardt and Rashmi Bansal for providing the antibodies against TrkA and Olig2. We thank Drs. Alexandra Joyner, John Rubenstein, and Mark Lewandoski for providing probes for RNA in situ hybridization analysis.

Correspondence should be addressed to James Y. H. Li, Department of Genetics and Developmental Biology, University of Connecticut Health Center, 400 Farmington Avenue, Farmington, CT 06030-6403. E-mail: jali@uchc.edu.

D0I:10.1523/JNEUROSCI.3742-10.2010

Copyright $\odot 2010$ the authors $\quad 0270-6474 / 10 / 3014824-11 \$ 15.00 / 0$ whereas those that undergo tangential migration form interneurons in the striatum (Marín et al., 2000). Although much progress has been made in understanding the development of the ventral telencephalon (Marín and Rubenstein, 2001; Wonders and Anderson, 2006), the molecular mechanism that differentiates striatal cholinergic interneurons from the cholinergic projection neurons in Ch1-4 remains to be elucidated.

In the striatum, cholinergic interneurons are differentially distributed in distinct functional and chemical compartments (Gerfen, 1992; Bernácer et al., 2007). Although striatal cholinergic interneurons, which are born between embryonic day 12 (E12) and E17 in rat, are the earliest born neurons in the striatum (Semba and Fibiger, 1988; Phelps et al., 1989), maturation of these neurons takes place after birth (Mobley et al., 1989; Gould et al., 1991). It has been shown that choline acetyltransferase (ChAT), the key enzyme for acetylcholine synthesis, is expressed in caudal-to-rostral and lateral-to-medial gradients in the dorsal striatum in rat during postnatal development (Semba and Fibiger, 1988; Phelps et al., 1989). However, little is known about the relationship among neurogenesis, distribution, and maturation of striatal cholinergic interneurons.

In the ventral telencephalon, the mouse homeobox gene $G b \times 2$ is expressed in the mantle zone (MZ) of the MGE (Bulfone et al., 1993). Interestingly, the expression of $G b \times 2$ is reduced in the MGE of $L h x 8$-deficient mice, in which the formation of forebrain cholinergic neurons is severely disrupted, suggesting that $G b \times 2$ may act downstream of $L h x 8$ to regulate the development of cholinergic neurons (Zhao et al., 2003). In this study, using inducible genetic fate mapping, we show that $G b \times 2$ lineage-derived cells that undergo tangential migration exclusively give rise to striatal 
cholinergic interneurons, whereas Gbx2-derived cells that undergo radial migration mainly give rise to GABAergic and other noncholinergic neurons in the basal forebrain. Inactivation of Gbx2 disrupts the migration of striatal cholinergic precursors, resulting in significant reduction and abnormal distribution of cholinergic interneurons in the striatum.

\section{Materials and Methods}

Animals and tissue preparation. The generation and genotyping of $G b \times 2^{C r e E R}$ knock-in and $G b \times 2$ conditional mutation, $G b \times 2^{F}$, have been described previously (Li et al., 2002; Chen et al., 2009). Nkx2.1-Cre BAC transgenic mice were reported previously (Xu et al., 2008). Mice were maintained on an outbred CD1 genetic background (Charles River Laboratories). All animal procedures described herein were approved by the Animal Care Committee at the University of Connecticut Health Center.

Noon of the day on which the vaginal plug was found was designated as E0.5. For inducible genetic fate mapping, $G b \times 2^{\mathrm{CreER} /+} ; R 26 R^{-1-}$ males, homozygous for the Cre reporter R26R (Soriano, 1999), were bred with wild-type or $G b \times 2^{+/-}$females (Wassarman et al., 1997). A total of 4-6 $\mathrm{mg}$ of tamoxifen (Sigma-Aldrich) in corn oil $(20 \mathrm{mg} / \mathrm{ml})$ was administered by oral gavage to pregnant females as described previously ( $\mathrm{Li}$ and Joyner, 2001). For tissue preparation, embryonic brains were fixed by immersion in $4 \%$ paraformaldehyde (PFA) at $4^{\circ} \mathrm{C}$ for $3-16 \mathrm{~h}$. Postnatal mice were deeply anesthetized and transcardially perfused with $4 \%$ PFA. Brains were postfixed in the same fixative overnight at $4^{\circ} \mathrm{C}$. For frozen tissue sections, brains were cryoprotected in $30 \%$ sucrose in PBS, rapidly frozen in OCT compound (Sakura Finetek), and sectioned with freezing microtome.

In situ hybridization, $\beta$-galactosidase, NADPH-diaphorase histochemistry and immunohistochemistry. Embryos or brains were processed for in situ hybridization as described previously (Guo and Li, 2007). Standard $\mathrm{X}$-gal staining was used to examine $\beta$-galactosidase $(\beta$-gal) activity (Nagy et al., 2003). To perform NADPH-diaphorase histochemistry, free-floating tissue sections were incubated with freshly made staining solution $(0.5 \mathrm{mg} / \mathrm{ml} \beta$-NADPH, $0.2 \mathrm{mg} / \mathrm{ml}$ nitroblue tetrazolium in $0.3 \% \mathrm{PBST}$ ) for $30 \mathrm{~min}$ to $2 \mathrm{~h}$ at $37^{\circ} \mathrm{C}$. Primary antibodies used in the study were as follows: mouse anti-5-bromo-2'-deoxyuridine (BrdU) (BD Biosciences), goat anti-ChAT and rabbit anti-DARPP-32 (Millipore Bioscience Research Reagents), rabbit anti-GABA (Sigma-Aldrich), rabbit anti-enhanced green fluorescent protein (EGFP) (Invitrogen), rat anti-EGFP (Nacalai Tesque), mouse anti-Isletl (DSHB), rat anti-Ki67 (Dako), rabbit anti-Olig2 (IBL), rabbit anti-pH3 (Millipore), rabbit antiCasp3 (cleaved) (Cell Signaling Technology), and rabbit anti-TrkA (courtesy of Dr. Louis Reichardt, University of California, San Francisco, San Francisco, CA). Secondary antibodies were as follows: Alexa fluorescent secondary antibodies (Invitrogen), and biotinylated rabbit anti-goat and biotinylated horse anti-rabbit (Vector Laboratories). Detailed protocols are available on the Li Laboratory website (http://lilab.uchc.edu/Pages/Protocols.html).

Cell counts and statistical analysis. The striatum in its entirety, including the caudate-putamen $(\mathrm{CPu})$, the nucleus accumbens $(\mathrm{Acb})$, and olfactory tubercle $(\mathrm{Tu})$, was determined using external anatomical landmarks based on a mouse atlas (Paxinos and Franklin, 2004). For cell profile counting in postnatal day 10 (P10) brains, sections from rostral, intermediate, and caudal levels of the corresponding structures were collected from three different animals. ChAT- or GABA-positive cells together with EGFP-positive cells were counted, and the ratio of doublepositive cells was calculated. To estimate the number of striatal cholinergic neurons in $\mathrm{P} 42$ brains, ChAT-positive cells were counted on every fifth coronal section (30 $\mu \mathrm{m}$ thick) throughout the whole $\mathrm{CPu}$, and every third coronal section throughout Acb and Tu. To quantify the ratio of BrdU- and ChAT-double-positive cells to total ChAT-positive cells in the striatum, comparable coronal sections from both control and conditional knock-out mice were collected at P10. At least three control and three mutant brains were analyzed for each experiment, and five sections from the rostral to caudal striatum were collected from each brain. Statistical significance was determined by Student's $t$ tests between mutant and control littermates using Microsoft Excel.
Morphometric analysis. Confocal images of green fluorescent protein (GFP) immunofluorescence of cholinergic precursor cells were captured by $Z$ sectioning on a Zeiss LSM510 Meta. Three-dimensional images were produced using LSM Software Zen (Zeiss) and the morphology of individual $\mathrm{GFP}^{+}$neurons was manually traced in Adobe Photoshop (Adobe Systems). Sholl analysis was performed by counting the number of neurite that cross a series of concentric circles at $5 \mu \mathrm{m}$ intervals from the center of soma. Statistical analysis for the Sholl dendritic analysis was performed with the Mann-Whitney $U$ test using Prism 4.0 (GraphPad).

In vitro migration assays. In vitro migration assay using matrix gel was performed as described previously (Liodis, 2007). Gbx $2^{+1-}$ females were mated with $G b \times 2^{C r e E R /+} ; R 26 R^{R F P /-}$ males, which carried a tdTomato Cre reporter (Madisen et al., 2010), and time-pregnant females were given tamoxifen at E10.5. Brains were dissected from E12.5 or E13.5 embryos in Leibovitz's L-15 medium, and brain slices (250 $\mu \mathrm{m}$ thickness) were prepared using a vibrotome (VT1000; Leica). Small tissue fragments containing $\mathrm{RFP}^{+}$striatal cholinergic precursors at the lateral ganglionic eminence (LGE)/MGE junction were dissected using tungsten needles and incubated for $1 \mathrm{~h}$ in L15/10 FCS at $37^{\circ} \mathrm{C}$. Explants were placed in a three-dimensional Matrigel (BD Biosciences) and cultured for $48 \mathrm{~h}$ in Neurobasal (supplemented with B27 and N2) medium in $3 \mathrm{~cm}$ plates. Explants were analyzed using an epifluorescence microscope (Axiovert 40 CFL; Zeiss). To compare the migration of control and Gbx2null cholinergic precursors in vitro, $24 \mathrm{RFP}^{+}$cells positioned furthest away from the center of each explant were selected and their distance from its edge was measured (three embryos for each genotype and three to four explants for each embryo). The average value of these measurements represented the maximum distance of cell migration from each explant. Statistical significance was determined by Student's $t$ tests.

\section{Results}

$G b x 2$ is expressed in a subset of $L h x 8$-positive cells after they exit the cell cycle in the ventral telencephalon

$G b \times 2$ expression is initiated in the ventral telencephalon of mouse embryos at E10.5 (Waters et al., 2003) (Fig. 1A). To examine the expression in greater detail, we used EGFP to follow $G b \times 2$ expression in a $G b \times 2^{C r e E R}$ knock-in mouse line. This mouse line contains an insertion of CreER-ires-Egfp cassette in the $5^{\prime}$-untranslated region of $G b \times 2$, so that the expression of both CreER and Egfp recapitulates the endogenous $G b \times 2$ expression (Chen et al., 2009) (supplemental Fig. S1, available at www.jneurosci.org as supplemental material). Double immunofluorescence for EGFP and BrdU or Ki67, which marks cells in active cell cycle, showed that $\mathrm{EGFP}^{+}$cells in the MGE were completely segregated from Ki67 ${ }^{+}$ or $\mathrm{BrdU}^{+}$progenitor cells in the ventral telencephalon at E11.5 and E12.5 (Fig. $1 B$; supplemental Fig. S2, available at www. jneurosci.org as supplemental material) (data not shown). Lhx8 is expressed in the subventricular zone and MZ of the MGE at E11.5 and E12.5, and is necessary for the expression of $G b \times 2$ (Zhao et al., 2003). Analysis of Gbx2 and $L h x 8$ transcripts on adjacent sections showed that the expression domain of $\operatorname{Lh} \times 8$ encompasses $G b \times 2{ }^{+}$cells, which are restricted to the ventral and medial part of the $L h x 8$-positive region in the MGE at E12.5 (Fig. $1 C, D)$. Therefore, $G b \times 2$ is probably induced in a subset of $L h \times 8$ expressing cells after they exit the cell cycle in the MGE.

\section{Gbx2-expressing cells in the ventral telencephalon contribute to the striatum and the basal forebrain}

It is known that MGE cells undergo radial and tangential migration and give rise to neurons in the basal forebrain, striatum, and cortex (Marín and Rubenstein, 2001). To determine the structures to which Gbx2-expressing cells contribute, we performed inducible genetic fate mapping. Tamoxifen was administered to pregnant females carrying $G b \times 2^{\mathrm{CreER} /+} ; R 26 R^{+/-}$embryos at E10.5 to induce Cre-mediated recombination and to perma- 
nently mark $G b x 2$-expressing cells with $\beta$-gal, which is expressed from the R26R allele (Soriano, 1999). As it has been shown that tamoxifen-induced labeling of CreER-expressing cells occurs in a window of 6-36 h (Joyner and Zervas, 2006), we deduced that administration of tamoxifen at E10.5 would likely label the Gbx2expressing cells between E11.0 and E12.0. At E12.5, a single cohort of X-gal ${ }^{+}$cells was detected in the MGE, recapitulating the endogenous $G b \times 2$ expression (Fig. $1 E, G)$. A few X-gal ${ }^{+}$cells, which are probably the frontrunners of tangentially migrating MGE cells, were found in the MZ of the LGE (Fig. 1E,G). From E13.5 onward, the labeled cells were segregated into two groups: the first one was tightly packed in the MZ of the MGE/POA, whereas the second group progressively moved toward the LGE with streams of $\mathrm{X}$-gal ${ }^{+}$cells extending into the $\mathrm{MZ}$ of the LGE (Fig. $1 F, H$ ). By P20, Gbx2-derived $\mathrm{X}$-gal ${ }^{+}$cells were found in the striatum, the basal magnocellular complex (Ch4), medial preoptic area (MPA), and to a lesser degree, in the horizontal limb of the diagonal band of Broca (HDB) (Ch3), the vertical limb of the diagonal band of Broca (VDB) (Ch2), the medial septum (MS) (Ch1), and the anterior amyloid area (AAD) (Fig. 1I,J). X-gal ${ }^{+}$cells were rarely detected in the cortex of Gbx $2^{\text {CreER/+ }} ; R 26 R^{+/-}$mice that received tamoxifen at E10.5 (Fig. 1 I). Fate-mapped Gbx2-expressing cells labeled by administering tamoxifen at E12.5 or E14.5 were found in the striatum and basal forebrain as those fate mapped at E10.5 (data not shown). In summary, we show that the Gbx2-expressing cells in the ventral telencephalon contribute to the striatum and the basal forebrain, but not to the cortex.

\section{Gbx2-expressing cells give rise to cholinergic interneurons in the striatum, but not to cholinergic projection neurons in the basal forebrain}

To determine the identity of neurons derived from the Gbx2 lineage, we first examined cholinergic neurons by immunohistochemistry for ChAT. In P42 Gbx2 $2^{\mathrm{CreER} /+}$; $R 26 \mathrm{R}^{+/-}$mice that received tamoxifen at E10.5, all X-gal ${ }^{+}$cells were positive for ChAT in the $\mathrm{CPu}$ and the Acb (Fig. 2A-C). In the Tu, many $\mathrm{X}_{\text {-gal }}{ }^{+}$cells were positive for ChAT $\left[\mathrm{ChAT}^{+} / \mathrm{X}-\right.$ $\mathrm{gal}^{+} \pm \mathrm{SD}$ (number of neurons analyzed): $36.7 \pm 4.9 \%$ (171)] (Fig. $2 B, D$ ). In contrast to the striatum, all X-gal ${ }^{+}$cells in Ch1Ch4 areas were negative for ChAT, except for the ventral pallidum (VP), where some X-gal ${ }^{+}$cells were positive for ChAT $[25.8 \pm 4.0 \%$ (146)] (Fig. 3A-G). These data demonstrate that Gbx2-expressing cells at E10.5 give rise to cholinergic neurons in the striatum, but noncholinergic neurons in the basal forebrain.

Because tamoxifen does not induce recombination in all CreER-expressing cells (Joyner and Zervas, 2006), inducible ge-

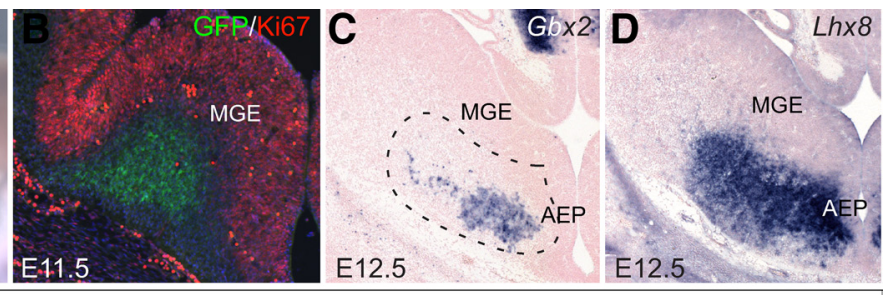

Administration of Tamoxifen at E10.5
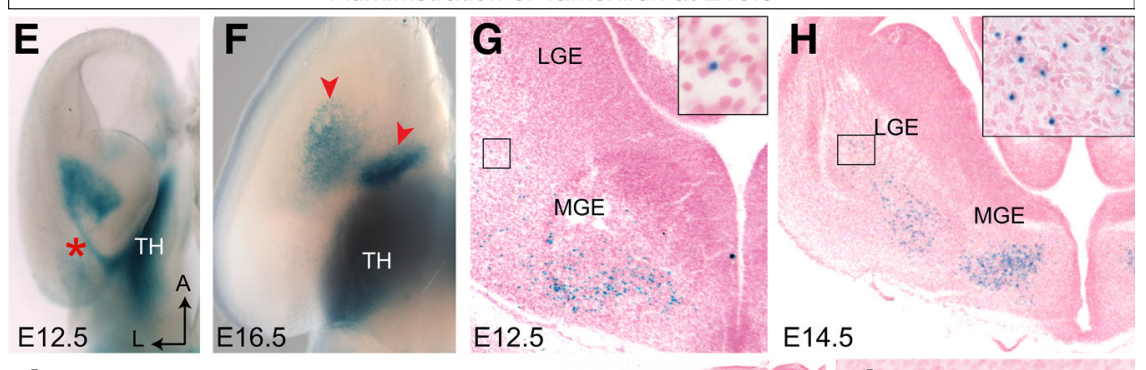

E14.5

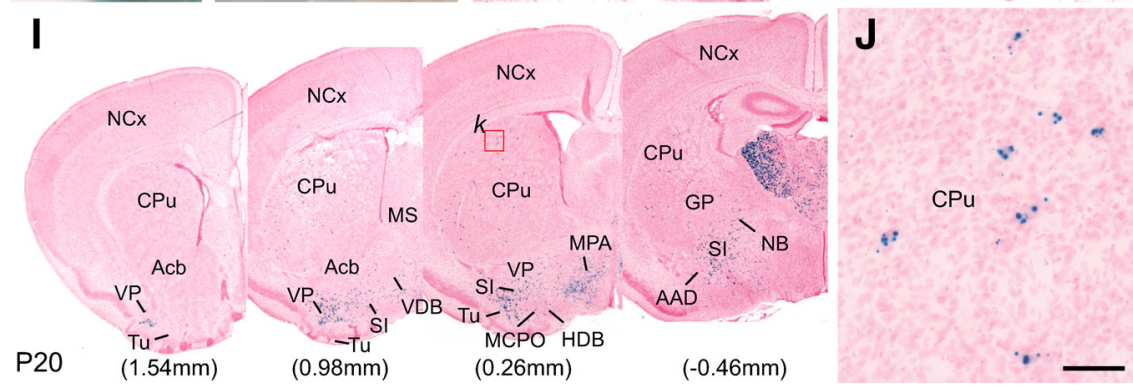

Figure 1. Gbx2-expressing cells contribute to the striatum and basal forebrain. $A$, In situ hybridization of Gbx2 in E10.5 brain. $B$ Double immunofluorescence for Ki67 and EGFP in the MGE of Gbx2 $2^{\text {reerR/+ }}$ embryos at E11.5. C, D, In situ hybridization of Gbx2 (C) (hx8 (D) on adjacent coronal sections of an E12.5 embryo. The dashed line outlines the $L h \times 8$ expression domain. $\boldsymbol{E}, \boldsymbol{F}$, Ventra dministration at E10.5. The boxed regions in $\boldsymbol{G}$ and $\boldsymbol{H}$ are magnified in the insets. $\boldsymbol{I}, X$-gal analysis of serial coronal sections, in an (n) alamus; Tu, olfactory tubercle; VDB, nucleus of the vertical limb of the diagonal band; VP, ventral pallidum. Scale bar: $B, 230 \mu \mathrm{m}$ C, D, G, $180 \mu \mathrm{m} ; \boldsymbol{H}, 300 \mu \mathrm{m} ; \boldsymbol{I}, 1100 \mu \mathrm{m} ; J, 60 \mu \mathrm{m}$.

netic fate mapping does not allow us to ascertain whether all striatal cholinergic neurons are derived from the Gbx2 lineage. To address this question, we explored EGFP as a possible lineage tracer to mark Gbx2-expressing cells and their descendents in $G b \times 2^{C r e E R /+}$ mice. We detected EGFP immunofluorescence in the striatum and basal forebrain in $G b \times 2^{C r e E R /+}$ mice as late as $\mathrm{P} 10$, and CreER transcripts in the same regions at $\mathrm{P} 4$ (data not shown). Importantly, all X-gal ${ }^{+}$cells were immunoreactive for EGFP in the striatum and basal forebrain in P10 Gbx2 $2^{\mathrm{CreER} /+}$; $R 26 R^{+/-}$mice that received tamoxifen at E10.5, demonstrating that the expression of EGFP persists and thus marks cells derived from the Gbx2 lineage in the ventral telencephalon of Gbx $2^{\text {CreER/+ }}$ mice (data not shown). Double immunofluorescence for ChAT and EGFP revealed that virtually all ChATpositive cells were positive for EGFP in the CPu and Acb [95.5 \pm $0.4 \%(524)$ and $91.3 \pm 9.1 \%$ (328), respectively] of $G b \times 2^{\text {CreER/+ }}$ mice $(n=3)$ (Fig. $2 E-J)$. Significantly, all EGFP ${ }^{+}$cells expressed ChAT ( $534 \mathrm{GFP}^{+}$cells analyzed from three mice), indicating that the $G b \times 2$ lineage exclusively gives rise to all cholinergic neurons in the $\mathrm{CPu}$ and $\mathrm{Acb}$. In the $\mathrm{Tu}$, although the majority of $\mathrm{ChAT}^{+}$ 

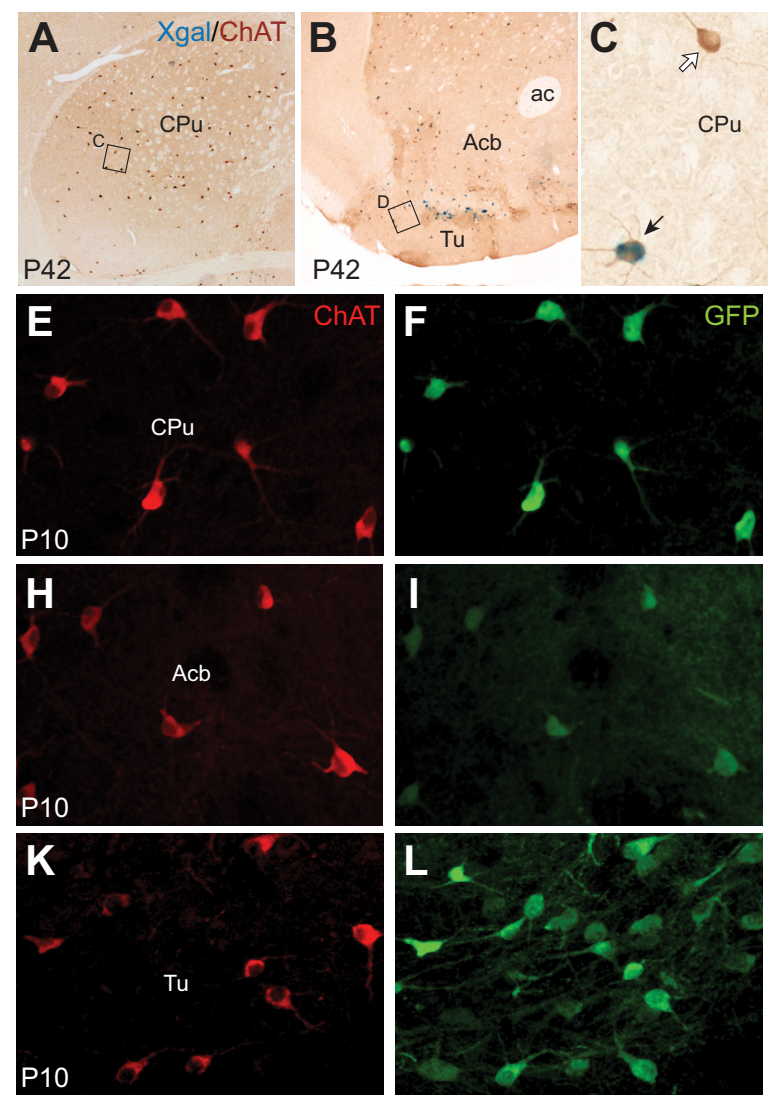

Figure 2. Striatal cholinergic interneurons are derived from the Gbx2 lineage. $\boldsymbol{A}-\boldsymbol{D}, \mathrm{X}$-gal histochemistry and ChAT immunohistochemistry on coronal sections of $\mathrm{P} 42 \mathrm{~Gb} \times 2^{\mathrm{CreER} /+} ; R 26 R^{+/-}$brains that received tamoxifen at E10.5. Note that all X-gal ${ }^{+}$ cells in the $\mathrm{CPu}(\boldsymbol{C})$ are immunoreactive for ChAT, whereas a few X-gal ${ }^{+}$cells in Tu $(\boldsymbol{D})$ are negative for ChAT. $\boldsymbol{E}-\boldsymbol{M}$, Double immunofluorescence of EGFP and ChAT on coronal sections of P10 Gbx2 $2^{\text {CreER/+ }}$ brain showing complete colocalization of EGFP and ChAT in the $\left(P u(E-G)\right.$ and $A c b(\boldsymbol{H}-\boldsymbol{J})$, and with only a few exceptions in Tu $(\boldsymbol{K}-\boldsymbol{M})$. The black arrows mark X-gal ${ }^{+} / \mathrm{ChAT}^{+}$cells; $^{\text {; }}$ the empty arrows mark X-gal ${ }^{-} / \mathrm{ChAT}^{+}(\boldsymbol{D})$ or EGFP $^{-} / \mathrm{ChAT}^{+}$cells $(\boldsymbol{M})$; the arrowheads mark X-gal ${ }^{+} / \mathrm{ChAT}^{-}(\boldsymbol{D})$ or EGFP $^{+} /$ ChAT ${ }^{-}$cells $(\boldsymbol{M})$. Scale bar: $\boldsymbol{A}, \boldsymbol{B}, 560 \mu \mathrm{m} ; \boldsymbol{C}-\boldsymbol{M}, 80 \mu \mathrm{m}$.

cells were positive for EGFP [77.4 $\pm 7.8 \%$ (217)], approximately one-half of the $\mathrm{EGFP}^{+}$cells were negative for ChAT $[50.2 \pm$ $11.2 \%$ (160)] (Fig. $2 K-M$ ). By contrast, all ChAT-positive neurons were negative for EGFP in $\mathrm{Ch} 4$ area, except for the VP, where many $\mathrm{ChAT}^{+}$neurons were positive for EGFP $[65.4 \pm 4.1 \%$ (124)] (Fig. 3H-N).

Next, we examined whether Gbx2-expressing cells contribute to GABAergic neurons by double immunofluorescence for GABA and EGFP. Many EGFP ${ }^{+}$cells in Ch4 were immunoreactive for GABA (Fig. 3O-R) [68.9 $\pm 5.5 \%$ (63) in magnocellular preoptic nucleus (MCPO), $76.6 \pm 7.3 \%$ (54) in nucleus basalis (NB), $72.2 \pm 13.7 \%(68)$ in substantia innominata (SI), $33.2 \pm$ $4.5 \%$ (63) in VP; three mice]. Together, our data show that the $G b \times 2$ lineage produces almost all cholinergic interneurons in the striatum. In the basal forebrain, however, the $G b \times 2$ lineage gives rise to GABAergic and other noncholinergic neurons.

\section{Contribution of the $G b \times 2$ lineage \\ to the striatum is dependent on \\ Gbx2 function}

The specific expression of $G b \times 2$ in striatal cholinergic interneurons suggests that $G b \times 2$ may play a role in the development of this population of cells. To investigate the function of $G b \times 2$, we first examined whether $G b \times 2$ inactivation alters expression of $N k \times 2.1$, $D l x 5, \operatorname{Lh} x 6, \operatorname{Lh} x 8$, Isl1, and Olig2, which are required for the specification, migration, and differentiation of MGE-derived cells, particularly development of cholinergic neurons (Sussel et al., 1999; Zhao et al., 2003; Alifragis et al., 2004; Furusho et al., 2006; Cobos et al., 2007; Elshatory and Gan, 2008). No discernable difference in the expression of these molecules was detected between the control littermates $\left(G b \times 2^{C r e E R /+}\right)$ and $G b \times 2^{C r e E R /-}$ mutants, which carry two different null alleles, $G b \times 2^{-}$and Gbx2 $2^{C r e E R}$ (Wassarman et al., 1997; Chen et al., 2009), at E11.5 and E12.5 (supplemental Fig. S3, available at www.jneurosci.org as supplemental material). Expression of $G b x 1$, which is closely related with $G b \times 2$ (Waters et al., 2003), in the MGE is unaffected in Gbx2 $2^{\text {CreER/- }}$ embryos at E11.5 and E12.5 (supplemental Fig. S4, available at www. jneurosci.org as supplemental material) (data not shown). These findings suggest that the initial formation of cholinergic precursors is unaffected in Gbx2-deficient embryos.

We next examined whether the differentiation of the striatal cholinergic precursors was affected in Gbx2 $2^{\mathrm{CrEER} /-}$ mice by taking advantage of the persistent expression of EGFP in these cells. The expression of EGFP was indistinguishable between $G b \times 2^{C r E E R /+}$ and $G b \times 2^{C r e E R /-}$ embryos at E11.5 and E12.5, demonstrating that the expression of EGFP in the

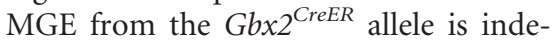
pendent on $G b \times 2$ function (supplemental Figs. S2, S3I-N, available at www. jneurosci.org as supplemental material). By E13.5, $\mathrm{EGFP}^{+}$cells were found throughout the LGE in Gbx2 $2^{C r e E R /+}$ embryos (Fig. $4 A$ ). In contrast, the majority of $\mathrm{EGFP}^{+}$cells were found near the junction between the LGE and MGE and there was a noticeable reduction of EGFP ${ }^{+}$cells in the dorsal and lateral-most areas of the LGE in Gbx $2^{\text {CreER/- }}$ embryos (Fig. $4 B$ ). To rule out that preferential absence of cholinergic precursors in the dorsal and lateral-most of LGE is caused by loss of EGFP expression in these cells deficient for $G b \times 2$, we fate mapped Gbx2-transcribing cells lacking Gbx2 protein in $G b \times 2^{\mathrm{CreER} /-} ; R 26 R^{+/-}$embryos. In $G b \times 2^{\mathrm{CreER} /+}$; $R 26 R^{+/-}$embryos, the fate-mapped Gbx2-transcribing cells labeled at E10.5 entered the prospective striatum along its lateral part at E14.5, and mainly contributed to the lateral-most area of the $\mathrm{CPu}$ at E18.5 (Fig. $4 E, G$ ). In the absence of $G b \times 2$, the fatemapped $G b \times 2$-transcribing cells mainly populated the center of the $\mathrm{CPu}$, avoiding the lateral area of the striatum in Gbx2 $2^{\mathrm{CreER} /-}$; R26R ${ }^{+/-}$embryos at E14.5 and E18.5 (Fig. 4F, H). Therefore, inactivation of $G b \times 2$ results in abnormal distribution of cholinergic precursors in the striatum.

Between E17.5 and P0, the overall number of EGFP ${ }^{+}$cells was significantly reduced and the reduction of $\mathrm{EGFP}^{+}$cells was more pronounced in the peripheral region, including the subcallosal streak, of the $\mathrm{CPu}$ in $\mathrm{Gb} \times 2^{\mathrm{CreER} /-}$ embryos (Fig. 4C,D; supplemental Fig. S5, available at www.jneurosci.org as supplemental material). Compared with those of control littermates, the numbers of $\mathrm{EGFP}^{+}$neurons on coronal sections of the $\mathrm{CPu}$ in Gb $\times 2^{C r e E R /-}$ embryos were reduced between $30.7 \%$ (E17.5) and 

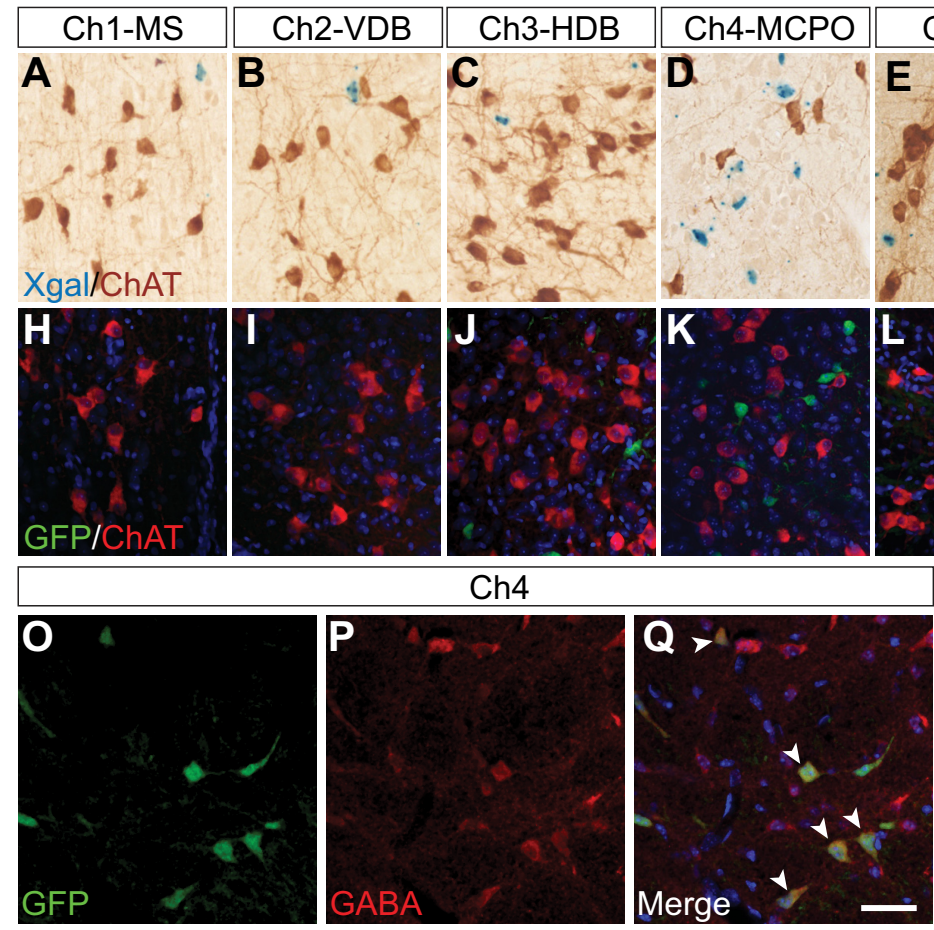

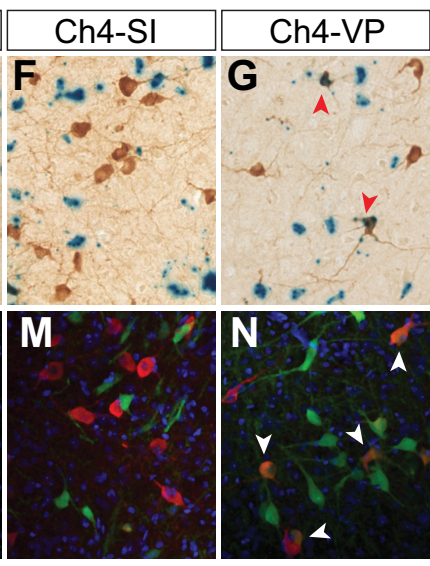

R

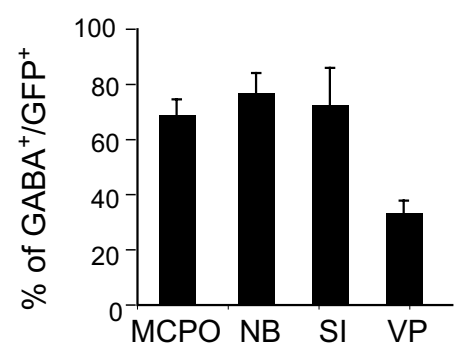

Figure 3. Forebrain cholinergic projection neurons are not derived from the $G b x 2$ lineage. $A-G, X$-gal and ChAT double labeling of various clusters of cholinergic projections neurons in Ch1-4 areas of $G b \times 2^{\text {CreER/+ }} ; R 26 R^{+/-}$mice at P42 after tamoxifen injection at E10.5. All X-gal ${ }^{+}$cells in the MS, VDB, HDB, MCPO, NB, and SI are negative for ChAT immunoreactivity. The red arrowheads mark a few $\mathrm{ChAT}^{+} / \mathrm{X}$-gal ${ }^{+}$cells in the VP. $\boldsymbol{H - N}$, Double immunofluorescence of EGFP and ChAT on coronal sections of P10 Gbx2 ${ }^{\text {CreER/+ }}$ brain. EGFP is absent in almost all ChAT ${ }^{+}$cells, except for a few in VP $\left(\boldsymbol{N}\right.$, white arrowhead). $\mathbf{0}-\mathbf{Q}$, Double immunofluorescence of EGFP $(\mathbf{0}), \mathrm{GABA}(\boldsymbol{P})$, and merged $(\boldsymbol{Q})$ on coronal sections of P10 Gbx2 ${ }^{\text {CreER/+ }}$ brain. Most EGFP ${ }^{+}$cells are GABAergic cells (white arrowhead) in (h4 region. $\boldsymbol{R}$, Histogram presentation of GABA ${ }^{+}$cells among EGFP ${ }^{+}$cells in Ch4 regions. Error bars indicate SD. Scale bar: $\boldsymbol{A}-\mathbf{Q}, 100 \mu \boldsymbol{m}$.

$44.8 \%(\mathrm{P} 0)$. To determine whether the reduction of $\mathrm{EGFP}^{+}$is caused by cell death, we examined apoptosis by double immunofluorescence for EGFP and active form of Caspase 3 (Casp3), a marker for apoptotic cells. No obvious increase of Casp $3^{+}$cells was detected in the LGE, MGE, and developing basal forebrain in Gbx2 $2^{\mathrm{CreER} /-}$ embryos at E12.5, E13.5, E14.5, and E17.5 (data not shown). Furthermore, Casp3 was rarely detected in EGFP ${ }^{+}$ cells in these brain regions in control or Gbx $2^{\text {CreER/- }}$ embryos. Therefore, caspase-mediated apoptosis is not responsible for the reduction of cholinergic precursors in the striatum of Gbx $2^{\mathrm{CreER} /-}$ embryos.

To examine the cellular morphology of striatal cholinergic precursors without $G b \times 2$, we marked these neurons using a $R 26 R^{Y F P}$ reporter (Srinivas et al., 2001), which uses yellow fluorescent protein (YFP) instead of $\beta$-gal to label Cre-mediated recombinant cells. Although anti-GFP antibodies detect both YFP and EGFP, the expression of YFP is expressed at a higher level than EGFP from the Gbx2 $2^{C r E R R}$ locus so that the robust YFP expression clearly marks a subset of $G b \times 2$-expressing cells, facilitating morphological analysis of migrating striatal cholinergic precursors. There was no discernable difference in the morphology of the YFP-labeled neurons between $G b \times 2$-deficient and their control littermates at E12.5 (data not shown). In E13.5 control embryos, the labeled Gbx2-derived cells in transit to the LGE displayed one or two leading processes and a trailing tail, the typical morphology of neurons that undergo tangential migration (Anderson et al., 1999) (Fig. 4 I; supplemental Fig. S5C, available at www.jneurosci.org as supplemental material). By contrast, the fate-mapped Gbx2-deficient neurons had increased number and branching of neurites in $G b \times 2^{C r e E R /-} ; R 26 R^{Y F P /+}$ embryos at E13.5 (Fig. $4 J-L$; supplemental Fig. S5C, available at www.jneurosci.org as supplemental material).
In summary, our data show that, although $G b \times 2$ is not essential for the patterning and specification of MGE cells, $G b \times 2$ is required for the differentiation of striatal cholinergic precursors. Loss of $G b \times 2$ results in reduction in number, and abnormal distribution and morphology of cholinergic precursors in the striatum.

\section{Loss of Gbx2 leads to a significant reduction of striatal cholinergic interneurons}

Gbx2-null mice die immediately after birth, precluding our study of striatal cholinergic interneuron differentiation and maturation, which occur between P1 and P35 in mice (Gould et al., 1991; Wassarman et al., 1997). To this end, we specifically removed $G b \times 2$ in the ventral telencephalon by combining a $G b \times 2$ conditional mutation allele, $G b \times 2^{F}$ (Li et al., 2002), with a transgenic mouse line that expresses Cre under the control of the $N k x 2.1$ promoter (Xu et al., 2008). $N k x 2.1$ is expressed in the ventricular zone of the MGE by E11.5, and the expression of Cre mimics the endogenous $N k \times 2.1$ expression in these transgenic mice (Xu et al., 2008). In mice carrying both Nkx2.1-Cre and R26R transgenes, Cre activity resulted in recombination throughout the ventral telencephalon encompassing the $G b \times 2$-expressing cells at E11.5 (supplemental Fig. S7 $L, M$, available at www.jneurosci.org as supplemental material). Moreover, all striatal cholinergic neurons were derived from $N k \times 2$.1-Cre-expressing cells (supplemental Fig. S7A-K, available at www.jneurosci.org as supplemental material). To examine the specific inactivation of $G b \times 2$, we performed in situ hybridization with a Gbx2 riboprobe corresponding to Gbx2 exon II, which is removed by Cre-mediated recombination. Gbx2 transcripts were mostly absent in the MGE of Gbx2 $2^{C r E E R / F}$; Nkx2.1-Cre embryos (designated as $G b \times 2-\mathrm{CKO})$ by E11.5, demonstrating that $G b \times 2$ is specifically inactivated in the ventral telencephalon in Gbx2-CKO mice 


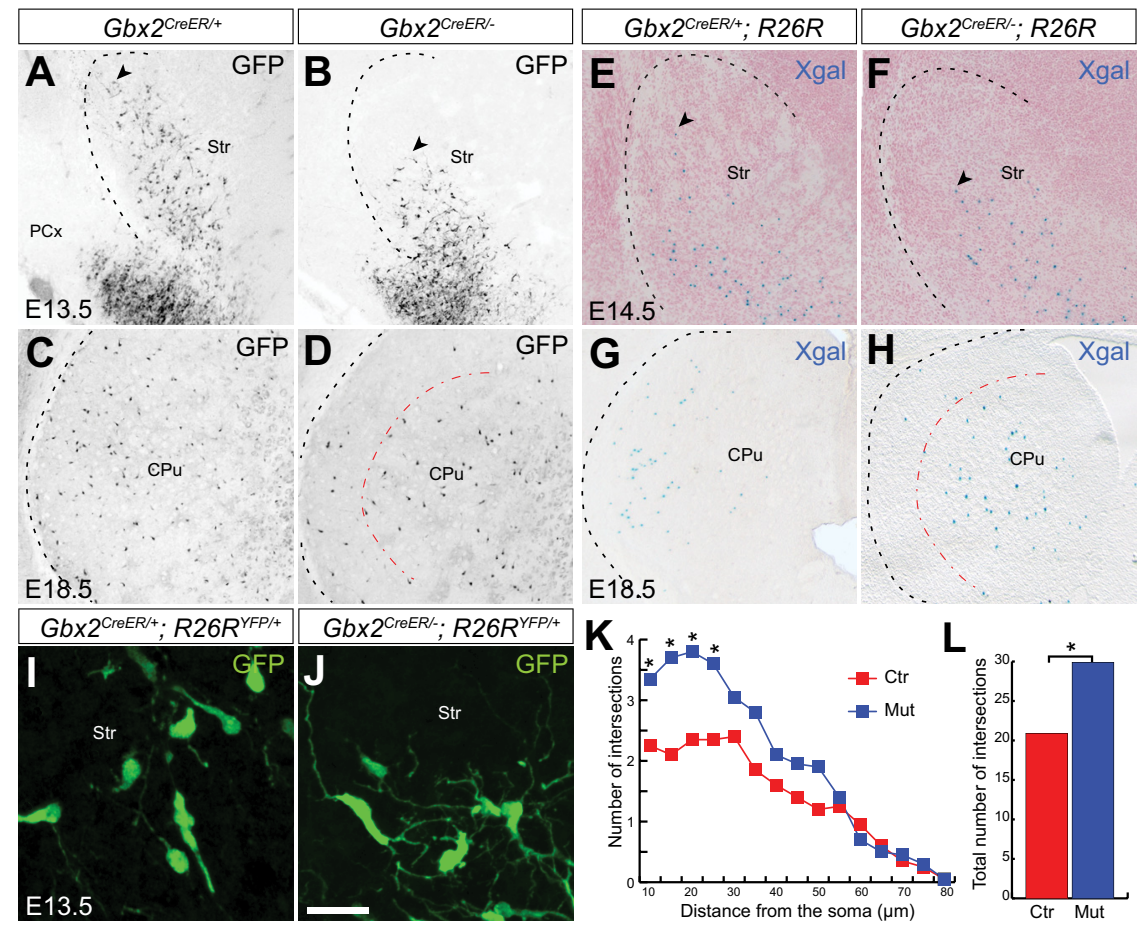

Figure 4. Loss of $G b \times 2$ results in abnormal migration and neurite outgrowth of cholinergic interneuron precursors. Immunofluorescence of EGFP on coronal sections of Gbx2 ${ }^{\text {CreER/+ }}(\boldsymbol{A}, \boldsymbol{C})$ and $G b \times 2^{\text {(reeR/- }}$ embryos $(\boldsymbol{B}, \boldsymbol{D})$ atE13.5 $(\boldsymbol{A}, \boldsymbol{B})$ and E18.5 (C, D). EGFP

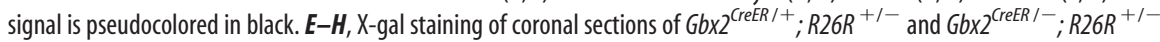
embryos at E14.5 $(\boldsymbol{E}, \boldsymbol{F})$ and E18.5 $(\boldsymbol{G}, \boldsymbol{H})$ after tamoxifen administration at E10.5. The dashed black line demarcates the lateral border of the striatum; the dashed red line indicates that EGFP ${ }^{+}$or X-gal ${ }^{+}$cells are mainly restricted to the center of the striatum; arrowhead marks the forefront of migrating cells. $I-L$, Confocal images of EGFP immunofluorescence of striatal cholinergic precursors in $G b x 2^{\text {CreeR } /+} ; R 26 R^{Y F P}$ and Gbx2 $2^{\text {CreER } /-} ; R 26 R^{Y F P}$ embryos at E13.5 $(\boldsymbol{I}, J)$ after tamoxifen administration at E10.5. $\boldsymbol{K}, \boldsymbol{L}$, Sholl analysis of striatal cholinergic precursors ( $n=20$ of each group) at E13.5. The asterisks indicate statistically significant difference ( $p<0.001$, Mann-Whitney U test). Scale bar: $\boldsymbol{A}, \boldsymbol{B}, \boldsymbol{E}, \boldsymbol{F}, 350 \mu \mathrm{m} ; \boldsymbol{C}, \boldsymbol{D}, \boldsymbol{G}, \boldsymbol{H}, 200 \mu \mathrm{m} ; \boldsymbol{I}, \boldsymbol{J}, 25 \mu \mathrm{m}$.

(supplemental Fig. S7 N,O, available at www.jneurosci.org as supplemental material).

Gbx2-CKO mice are viable and do not display any gross abnormality. We examined striatal cholinergic neurons in Gbx2-CKO mice between $\mathrm{P} 2$ and $\mathrm{P} 42$ by ChAT immunohistochemistry. Consistent with the reduction of striatal cholinergic precursors $\left(\mathrm{EGFP}^{+}\right)$ found in Gbx2 $2^{C r e E R /-}$ embryos by E17.5 and P0 (Fig. 4D; supplemental Fig. S5, available at www.jneurosci.org as supplemental material), the number of $\mathrm{ChAT}^{+}$cells was considerably reduced in $G b \times 2-C K O$ mice $(n=3)$ by $\mathrm{P} 2$ (Fig. $5 D)$. At P42, there was a significant reduction of cholinergic neurons in the $\mathrm{CPu}(35 \pm 1.2 \%)$, $\operatorname{Acb}(29 \pm 4.3 \%)$, and the $\mathrm{Tu}(50 \pm 11.0 \%)$ in $G b x 2-\mathrm{CKO}$ mice $(n=$ $3)$. In addition to the reduction in the overall number, the cholinergic neurons displayed abnormal expression pattern of ChAT and altered distribution within the striatum of Gbx2-CKO mice. Only weak expression of ChAT was detected in cholinergic neurons throughout the striatum in control $\left(\mathrm{Gb} \times 2^{\mathrm{CreER} /+} ; \mathrm{Nk} \times 2.1-\mathrm{Cre}\right)$ and Gbx2-CKO mice at P2 (Fig. 5A,B). At P4, cholinergic neurons in the lateral and caudal parts of the $\mathrm{CPu}$ displayed significantly higher levels of ChAT than those in the rostral and medial part of the $\mathrm{CPu}$ $(n=4)$ (Fig. $5 F-H)$. By contrast, robust ChAT expression was detected in cholinergic neurons throughout the $\mathrm{CPu}$ of $\mathrm{P} 4 \mathrm{~Gb} \times 2-\mathrm{CKO}$ mice (Fig. $5 I-K$ ). In control mice, by P6, strong ChAT expression was detected in cholinergic neurons throughout the striatum, suggesting that the maturation of cholinergic neurons is mostly complete by P6 (Fig. 5C). Compared with control animals, $\mathrm{ChAT}^{+}$cells were fewer in number, particularly in the lateral and dorsal-most of the $\mathrm{CPu}$ in $\mathrm{P} 6 \mathrm{Gbx2}-\mathrm{CKO}$ mice $(n=3)$ (Fig. $5 E)$. In the $\mathrm{CPu}$ of
Gbx2-CKO mice at P42, the loss of cholinergic neurons was more prominent in the midsegment than the anterior or posterior segment, and the remaining cholinergic neurons were mainly found in the center of the nucleus (Fig. 6B, F). Therefore, inactivation of $G b \times 2$ leads to reduction in number and abnormal distribution of cholinergic neurons in the striatum.

To determine whether the defect in the striatum of Gbx2-CKO mutants is specific to the cholinergic system, we examined GABAergic interneurons that express nitric oxide synthase (NOS), which also originate from the MGE, and striatal projection neurons, which are generated in the LGE and express dopamine- and cAMPregulated phosphoprotein (Darpp-32) (Marín et al., 2000). Examination of these neurons by histochemical staining for NADPH-diaphorase and immunofluorescence for Darpp-32 revealed that there was no difference in the number and the distribution of $\mathrm{NOS}^{+}$and Darpp- $32^{+}$cells in the striatum between control littermates and Gbx2-CKO mice at P42 (supplemental Figs. S5, S8, available at www.jneurosci.org as supplemental material).

In summary, deletion of $G b \times 2$ in the ventral telencephalon leads to significant reduction in the number and abnormal distribution of striatal cholinergic neurons. Furthermore, defects in the striatum are mostly restricted to the cholinergic system in Gbx2-CKO mice.

\section{Development of striatal cholinergic interneurons is independent of $G b x 2$ after birth}

As $G b \times 2$ expression persists in striatal cholinergic interneurons after birth (Fig. $2 E-M$ ) (data not shown), we next investigated whether $G b \times 2$ plays a role during postnatal development of these neurons. No obvious difference was found in the morphology of striatal cholinergic neurons between control and Gbx2-CKO mice at P0, P4, P6, and P42 (Figs. 6A, $B, 7$, insets). We examined expression of Isll and the tyrosine kinase receptor TrkA, which is known to play an important role in the maturation and survival of striatal cholinergic neurons (Fagan et al., 1997; Elshatory and Gan, 2008). Double immunofluorescence for EGFP and Isl1 or TrkA showed that all EGFP ${ }^{+}$cells express Isl1 or TrkA in the CPu of control and Gbx2-CKO mice at P0 and P4 (Fig. 7A-F"). No discernable change in the expression of Isl1 or TrkA was detected in the striatum of Gbx2-CKO mice. Similarly, all $\mathrm{EGFP}^{+}$cells were positive for ChAT in the striatum of the control littermates and $G b \times 2-\mathrm{CKO}$ mice at P6 (Fig. $\left.7 G, H^{\prime \prime}\right)$. In addition, examination of cell death by immunofluorescence for Casp3 and terminal deoxynucleotidyl transferase-mediated biotinylated UTP nick end labeling assay did not detect any increase in cell death in the striatum of Gbx2-CKO mice at P2, P4, and P10 (data not shown). Our molecular marker analyses suggest that $G b \times 2$ is not essential for the development of striatal cholinergic interneurons after birth. 


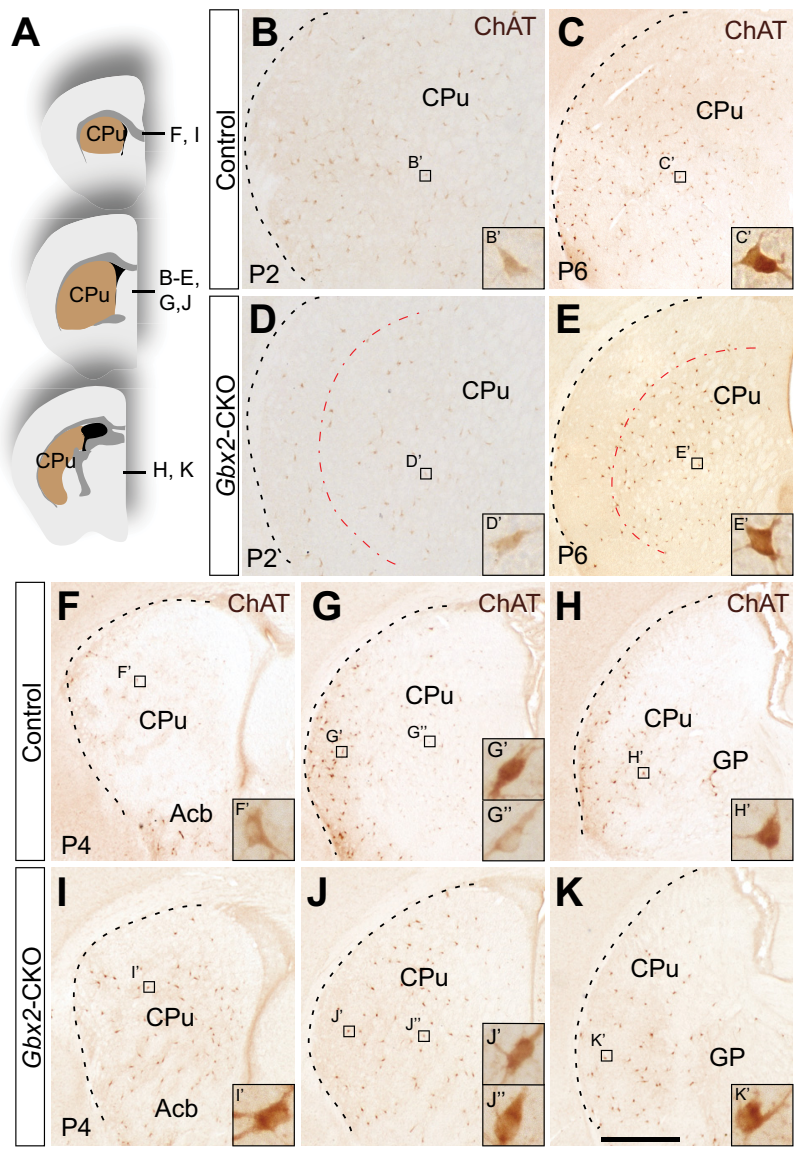

Figure 5. Specific deletion of $G b \times 2$ in the MGE results in significant reduction and aberrant distribution of cholinergic interneurons in the striatum. $A$, A schema shows the relative locations of $\boldsymbol{B}-\boldsymbol{K} \cdot \boldsymbol{B}-\boldsymbol{E}$, ChAT immunohistochemistry on coronal sections of control brains and Gbx2CKO brains at $P 2$ and $P 6$. Note the homogeneous level, which is low at $P 2$ but high at $P 6$, of ChAT expression in cholinergic neurons throughout the striatum of the control and Gbx2-CKO mice. In the mutant brain, the number of $\mathrm{ChAT}^{+}$cells is significantly reduced, particularly in the peripheral regions (between the black and red dashed lines). The morphology and ChAT expression of representative neurons (boxed area in $\boldsymbol{B}-\boldsymbol{E}$ ) are shown in insets. $\boldsymbol{F}-\boldsymbol{K}$, ChAT immunohistochemistry on serial coronal sections of the CPu at P4. In the control mice $(\boldsymbol{F}-\boldsymbol{H})$, the levels of ChAT expression exhibit caudal $>$ rostral $(\boldsymbol{F}-\boldsymbol{H})$ and lateral $>$ medial $(\boldsymbol{G})$ gradients. By contrast, in Gbx2-CK0 mice at P4 (I-K), all cholinergic neurons throughout the CPu display levels of ChAT expression similar to those in the caudal and lateral CPu in the control littermates. Typical $\mathrm{ChAT}^{+}$neurons $(\boldsymbol{F}-\boldsymbol{K}$, boxed area) are shown in insets. The lateral border of the CPu is marked by the black dashed line. Scale bar: $\boldsymbol{B}, \boldsymbol{D}, 1300 \mu \mathrm{m} ; \boldsymbol{C}, \boldsymbol{E}, 3000 \mu \mathrm{m} ; \boldsymbol{F}-\boldsymbol{K}, 2500 \mu \mathrm{m}$.

\section{Preferential reduction of late-born striatal cholinergic interneurons attributable to loss of $G b x 2$}

Based on birth-dating analysis in rat (Phelps et al., 1989), we deduced that striatal cholinergic neurons are likely born between E10.5 and E14.5 in mice. We observed that the fate-mapped Gbx2-expressing cells at E10.5 mainly contributed to the lateral part of the striatum, where cholinergic neurons first expressed high level of ChAT at P4 (Figs. 4G, 5G), suggesting that earlyborn striatal cholinergic neurons may mature first. Interestingly, in Gbx2-CKO mice, all cholinergic neurons uniformly expressed high level of ChAT at P4 (Fig. 5I-K). These findings raise the possibility that, in the absence of $G b \times 2$, the remaining striatal cholinergic interneurons may be mainly born at the early stage, whereas late-born striatal cholinergic interneurons fail to develop. To test this hypothesis, we performed birth-dating analysis by administering BrdU to pregnant mice carrying Gbx2-CKO embryos between E10.5 and E15.5. Cells that undergo their last S-phase at the time of BrdU injection will retain BrdU, whereas

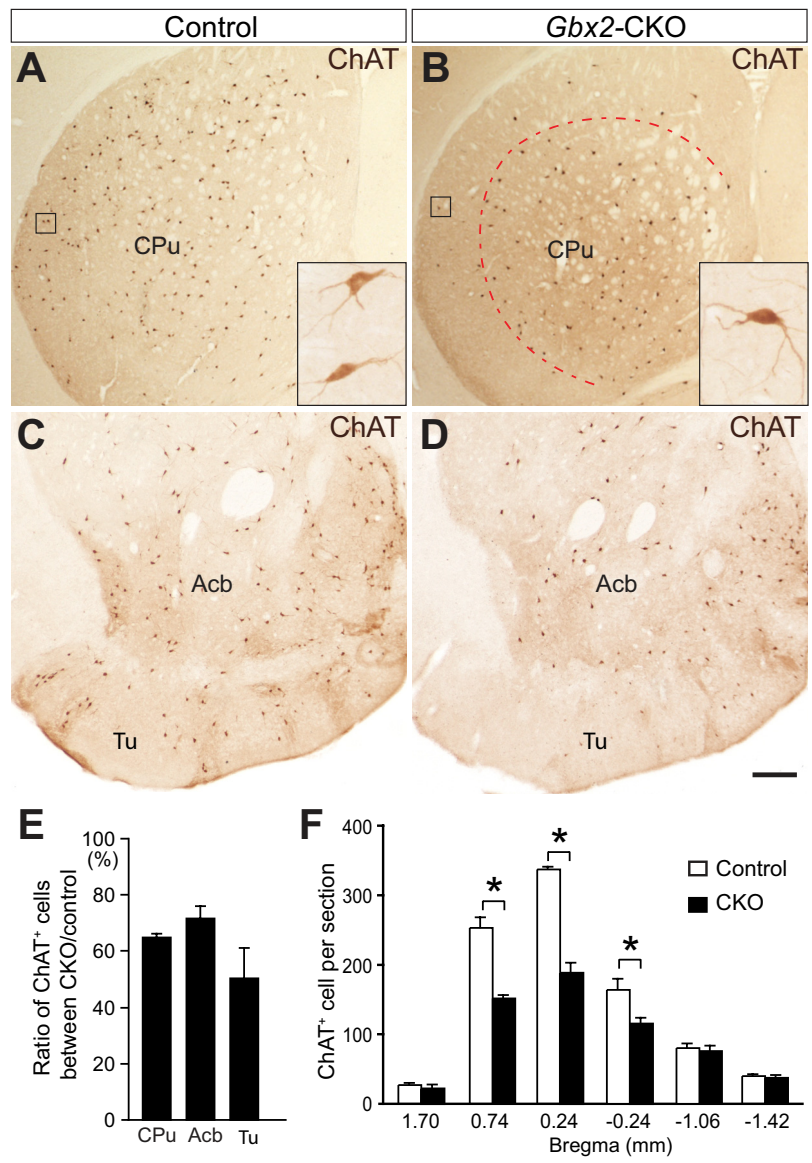

Figure 6. Significant reduction of striatal cholinergic interneurons in adult GbX2-CKO mice. $A-D$, ChAT immunohistochemistry on coronal sections of the striatum of control $(A, C)$ and Gbx2-CKO $(\boldsymbol{B}, \boldsymbol{D})$ mice at P42. The insets show the morphology of typical ChAT ${ }^{+}$cells; the red dashed line delineates the center of the $\mathrm{CPu}$, to which most $\mathrm{ChAT}^{+}$neurons are restricted in Gbx2-CKO mutants. $\boldsymbol{E}$, Histogram of the ratio of $\mathrm{ChAT}^{+}$cells in $\mathrm{CPu}, \mathrm{Acb}$, and Tu between CKO and control mice ( $n=3$ each) at P42.F, Comparison of the total count of ChAT ${ }^{+}$cells in coronal sections of $\mathrm{CPu}$ at different rostrocaudal levels between control and Gbx2-CKO mice $(n=3$ each). The asterisks indicate statistical significance ( $p<0.05$, Student's $t$ test). Error bars indicate SD. Scale bar: $A, B, 500 \mu \mathrm{m} ; C, D, 600 \mu \mathrm{m}$.

cells that continue to cycle dilute the label over time (Howell et al., 1997). Double immunofluorescence for ChAT and BrdU at P10 revealed that the majority of striatal cholinergic neurons were born between E11.5 and E14.5, and few striatal cholinergic neurons were born before E11.5 and after 14.5 (Fig. 8A-C) (data not shown). There was no significant difference in the percentage of cholinergic neurons born at E11.5 between control and Gbx2$\mathrm{CKO}$ (Fig. $8 \mathrm{~A}$ ). However, the striatal cholinergic neurons that are born at E12.5 were significantly reduced in Gbx2-CKO mutants, and virtually no E14.5-born cholinergic neurons were detected in the mutants at P10 $(n=3)$ (Fig. $8 A-C)$. These data demonstrate that the cholinergic neurons that are born after E12.5 are preferentially affected because of the loss of $G b x 2$.

\section{Discussion}

Gbx2-expressing cells in the MGE differentially contribute to striatal cholinergic interneurons and noncholinergic neurons in the basal forebrain

Transplantation studies first suggested that striatal cholinergic interneurons are derived from the MGE (Olsson et al., 1998), and this notion was subsequently supported by genetics experiments (Sussel et al., 1999; Marín et al., 2000). Using inducible genetic 


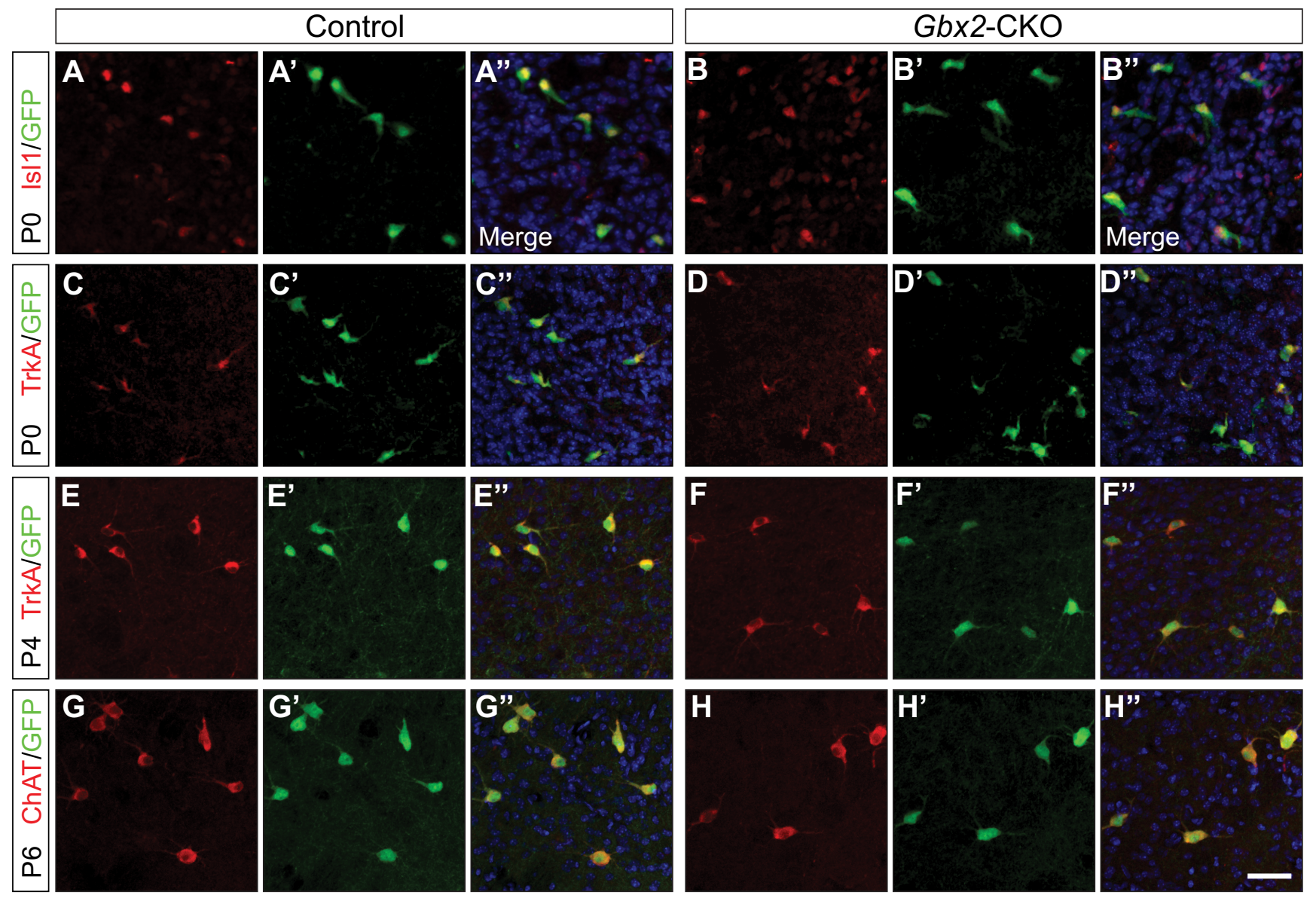

Figure 7. Differentiation of striatal cholinergic interneurons during early postnatal stages is unaffected by the loss of $G b \times 2 . A-H^{\prime \prime}$, Double immunofluorescence of EGFP and Is 11 or TrkA on coronal sections of the CPu in control and Gbx2-CKO mice at P0, P4, and P6. Note that the expression of Is 11 and TrkA is detected in all EGFP ${ }^{+}$neurons, and there is no difference between Gbx2-CK0 and their control littermates. Scale bar, $50 \mu \mathrm{m}$.

fate mapping and EGFP as lineage tracer, here we provide definite evidence showing that Gbx2-expressing cells in the MGE that undergo tangential migration exclusively give rise to nearly all cholinergic interneurons in the $\mathrm{CPu}$ and $\mathrm{Acb}$. Interestingly, in the $\mathrm{Tu}, \sim 20 \%$ of cholinergic neurons are not derived from the $G b \times 2$ lineage, whereas some $G b \times 2$-derived cells become noncholinergic neurons (Fig. $2 D, K-L$ ). These results indicate that the Tu has different and heterogeneous developmental ancestry compared with the $\mathrm{CPu}$ and $\mathrm{Acb}$.

In contrast to those undergoing tangential migration, the fatemapped Gbx2-derived cells that remain in the MGE give rise to GABAergic and other noncholinergic neurons in the basal forebrain, indicating that the Gbx2-expressing cells in the MGE are heterogeneous. Our preliminary study shows that misexpression of Gbx2 in all Nkx2.1-expressing cells does not affect the specification or differentiation of cholinergic and GABAergic neurons derived from the MGE, indicating that Gbx2 does not act as a determinant for the differentiation of striatal cholinergic interneurons (Sunmonu et al., 2009). Therefore, factors acting upstream of $G b \times 2$ may be required to specify and differentiate cholinergic interneurons and projection neurons. Previous studies identified $\operatorname{Lh} x 8$ as the key regulator for the development of both cholinergic interneurons and projection neurons in the ventral forebrain (Zhao et al., 2003; Mori et al., 2004; Fragkouli et al., 2005). Results from our current study suggest that $L h \times 8^{+} / G b \times 2^{+}$ cells contribute to the striatum and form cholinergic interneurons, and that $L h \times 8^{+} / G b \times 2^{-}$cells contribute to the cholinergic projection neurons in the basal forebrain (Fig. $8 E$ ). Since $L h x 8$ cells in the MGE are known to give rise to GABAergic neurons (Fragkouli et al., 2005), $L h \times 8^{+} / G b \times 2^{+}$cells that undergo radial migration may also give rise to GABAergic and other noncholinergic neurons in the basal forebrain. Interestingly, $G b \times 1$, a paralogue of $G b x 2$, is apparently expressed in the basal forebrain cholinergic projection neurons (Asbreuk et al., 2002). Therefore, the two major groups of cholinergic neurons in mammalian forebrain appear to be differentially demarcated by $G b \times 1$ and $G b \times 2$, which were duplicated during evolution (Rhinn et al., 2003, 2004; Waters et al., 2003).

The temporal order of neurogenesis correlates with the location and progressive maturation of cholinergic interneurons in the striatum

We found that most striatal cholinergic interneurons are generated before E14.5, with $>50 \%$ of the neurons being generated before E12.5 in mice (Fig. 8) (data not shown). As Gbx2 expression is initiated in striatal cholinergic precursors after they exit the cell cycle (Fig. 1B), tamoxifen-induced labeling of Gbx2expressing cells at E10.5 likely fate maps the early-born striatal cholinergic interneurons. We found that fate-mapped Gbx2expressing cells at E10.5 preferentially contribute to the lateral part of CPu (Fig. 4G), suggesting that striatal cholinergic neurons are probably arranged in a lateral-to-medial order in the $\mathrm{CPu}$ according to the temporal order of genesis of these neurons. Intriguingly, this orderly deposition of striatal cholinergic neurons 

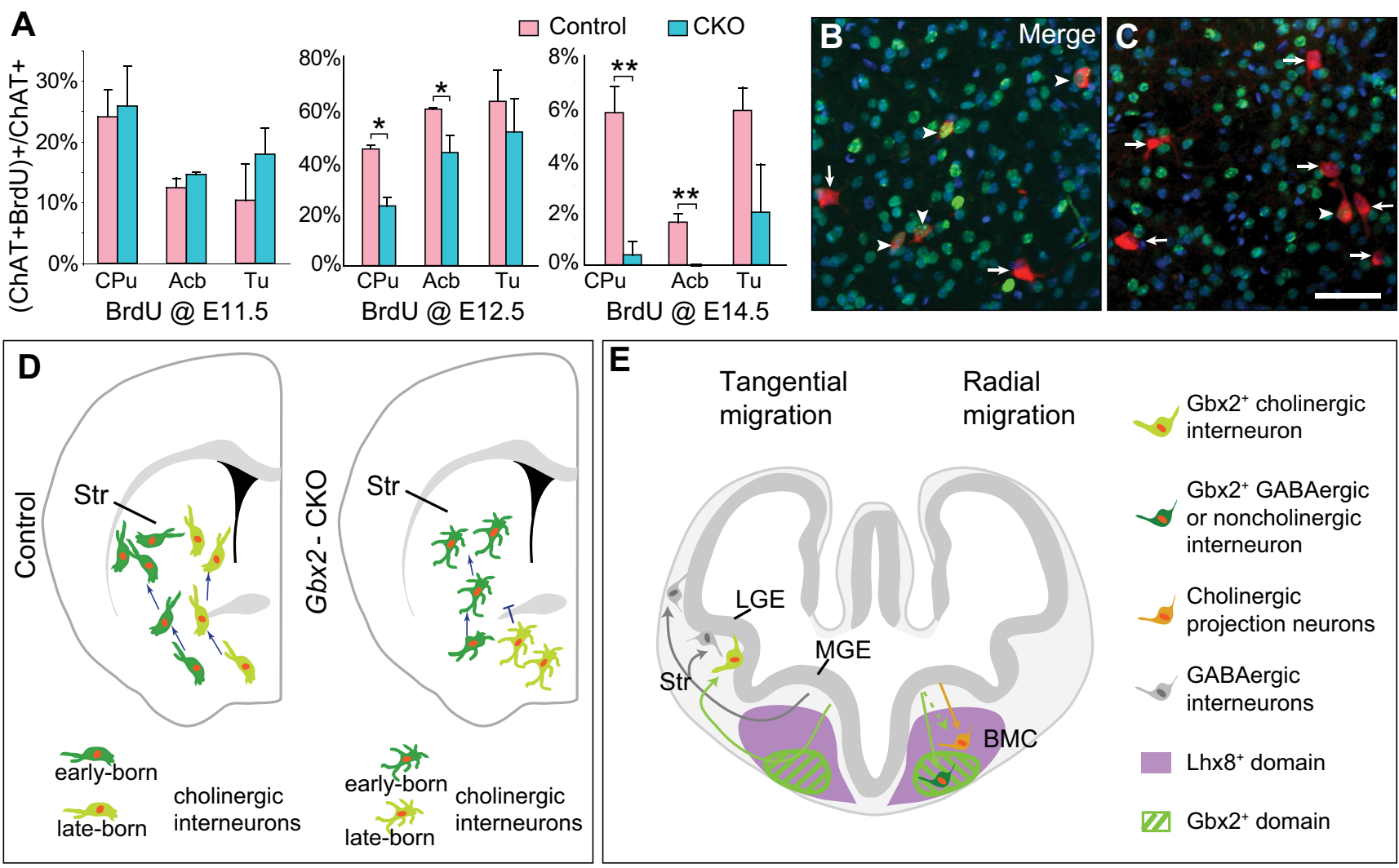

Figure 8. Late-born striatal cholinergic interneurons are preferentially lost in the absence of $\mathrm{Gbx2}$. A, Histograms of the ratio of $\mathrm{ChAT}^{+} / \mathrm{BrdU}^{+}$over $\mathrm{ChAT}^{+}$cells in the CPu, $\mathrm{Acb}$, and Tu of control and Gbx2-CKO littermates ( $n=3$ each) at P12 after BrdU administration at E11.5, E12.5, and E14.5. The single and double asterisks indicate significant difference, $p<0.05$ and $p<0.01$, respectively, with Student's $t$ test. Error bars indicate SD. B, C, Double immunofluorescence of ChAT and BrdU on coronal sections of the CPu of control (B) and Gbx2-CKO (C) mice at P12 after administration of BrdU at E12.5. There is a noticeable reduction of $\mathrm{ChAT}^{+} / \mathrm{BrdU}^{+}$cells (arrowheads) in Gbx2-CKO. D, Schematic representation of potential defects in migration of early versus late-born striatal cholinergic interneurons. $E$, Schematic summary of differentiation of precursor cells originating from the MGE. Scale bar: $B, C, 50 \mu \mathrm{m}$.

in the $\mathrm{CPu}$ appears less prominent at 3 weeks after birth (Fig. 1I), suggesting a continued cellular rearrangement during postnatal development.

In agreement with previous findings (Phelps et al., 1989; Gould et al., 1991), we show that striatal cholinergic neurons in the lateral side of the $\mathrm{CPu}$ display higher levels of ChAT immunoreactivity than those in the medial $\mathrm{CPu}$ at $\mathrm{P} 4$, but by $\mathrm{P} 6$, all striatal cholinergic interneurons express uniform and robust ChAT expression (Fig. 5). These observations suggest that the maturation of cholinergic interneurons progresses from the lateral-to-medial direction in the $\mathrm{CPu}$, and this maturation order thus correlates with the temporal order of neurogenesis. Members of the neurotrophin family, particular nerve growth factor (NGF), are known to play an important role in promoting maturation and survival of cholinergic neurons in the striatum and basal forebrain (Hefti, 1986; Lucidi-Phillipi et al., 1996). NGF administration increased Chat mRNA levels, and conversely, anti-NGF serum infusion suppressed expression of Chat in the forebrain of rat (Li et al., 1995). Furthermore, in the absence of $\operatorname{trkA}$, a receptor for NGF, striatal cholinergic interneurons have reduced ChAT expression at P7/8 (Fagan et al., 1997). Therefore, the progressive maturation of striatal cholinergic interneurons may be regulated by the spatial or temporal gradient of NGF signaling in the striatum. However, in Gbx2-CKO mice, the remaining cholinergic neurons, which are mostly early-born and abnormally reside in the medial part of the $\mathrm{CPu}$, express robust ChAT similar to the early-born cholinergic neurons, arguing against the notion that a spatial gradient of NGF determines mat- uration progression of striatal cholinergic interneurons (Fig. 5). Instead, our results suggest that an intrinsic mechanism associated with the temporal order of neurogenesis, probably by controlling the responsiveness to NGF signals, determines the maturation order of striatal cholinergic interneruons.

Different effects on the development of early-born and late-born striatal cholinergic interneurons because of loss of $G b \times 2$

By fate mapping Gbx2-transcribing cells in Gbx2-deficient embryos at E10.5, we show that early-born cholinergic precursors shift their migration route medially contributing to the medial, rather than the lateral, part of the $\mathrm{CPu}$ (Fig. $4 F, D$ ). As Gbx2expressing cells that undergo tangential migration are embedded among the developing thalamocortical and corticothalamic axons, which are mostly abolished in Gbx2-deficient embryos (Miyashita-Lin et al., 1999; Hevner et al., 2002), it is possible that the abnormal distribution of striatal cholinergic neurons may be related to the loss of these axons. However, similar abnormal distribution of cholinergic interneurons was found in the $\mathrm{CPu}$ of the Gbx2-CKO mutants, where thalamocortical and corticothalamic projections develop normally (data not shown), demonstrating that the development of the thalamocortical axons and tangential migration of the Gbx2-expressing cells in the MGE are mutually independent. In addition, we found that tangentially migrating Gbx2-derived cells that were labeled at E10.5 display abnormal neurite outgrowth and increased neurite complexity (Fig. 4I-L). These data suggest that loss of Gbx2 may affect the migration of early-born striatal cholinergic interneurons. The 
potential defect in migration may account for the abnormal distribution of cholinergic neurons found in the striatum of Gbx2null and Gbx2-CKO mutants. To investigate the potential defect in migration of striatal cholinergic neurons, we performed migration assay in matrix gel. However, no noticeable difference in the number and distance of migration of control and Gbx2-null cholinergic precursors was detected, suggesting that Gbx2deficient cells are not impaired in general cell migration (supplemental Fig. S9, available at www.jneurosci.org as supplemental material). Future study is necessary to determine the molecular mechanism underlying the function of $G b \times 2$ in regulating migration of striatal cholinergic neurons.

In addition to the abnormal distribution, there is a significant reduction of cholinergic interneurons in the striatum because of the loss of $G b \times 2$. By examining $\mathrm{EGFP}^{+}$cells in the striatum, we detected a significant reduction in the number of striatal cholinergic precursors in Gbx2 $2^{\mathrm{CreER} /-}$ mutants, $30.7 \%$ at E17.5 and $44.8 \%$ at $\mathrm{P} 0$. The reduction of $\mathrm{EGFP}^{+}$cells in $\mathrm{Gb} \times 2^{\mathrm{CreER} /-} \mathrm{em}-$ bryos at these stages is comparable with the $35 \%$ reduction of striatal cholinergic neurons that were examined by ChAT in the $\mathrm{CPu}$ of $\mathrm{Gb} \times 2-\mathrm{CKO}$ mice, demonstrating that the reduction of striatal cholinergic neurons is caused by a loss of cholinergic precursors by E17.5 (Fig. 6). Interestingly, labeling progenitors that undergo their last mitosis by BrdU incorporation showed that there was no significant difference in the number of striatal cholinergic neurons born at E11.5 between control and Gbx2-CKO mice, and that there was a dramatic and disproportionate reduction of the striatal cholinergic neurons that were born after E12.5 in Gbx2-CKO mice (Fig. 8). These observations collectively suggest that development of late-born striatal cholinergic interneurons is preferentially affected in the absence of $G b \times 2$. Because $G b \times 2$ expression is maintained in the migrating cholinergic precursors, we cannot specifically fate map Gbx2-expressing cells after E12.5 without marking the neurons that are born earlier. Therefore, we cannot definitively determine the fate of late-born cholinergic neurons in the Gbx2 mutant mice. Future experiments are required to determine the distinct requirement for Gbx2 in development of the early-born and late-born striatal cholinergic interneruons.

\section{References}

Alifragis P, Liapi A, Parnavelas JG (2004) Lhx6 regulates the migration of cortical interneurons from the ventral telencephalon but does not specify their GABA phenotype. J Neurosci 24:5643-5648.

Anderson S, Mione M, Yun K, Rubenstein JL (1999) Differential origins of neocortical projection and local circuit neurons: role of Dlx genes in neocortical interneuronogenesis. Cereb Cortex 9:646-654.

Asbreuk CH, van Schaick HS, Cox JJ, Kromkamp M, Smidt MP, Burbach JP (2002) The homeobox genes Lhx7 and Gbx1 are expressed in the basal forebrain cholinergic system. Neuroscience 109:287-298.

Berger-Sweeney J (2003) The cholinergic basal forebrain system during development and its influence on cognitive processes: important questions and potential answers. Neurosci Biobehav Rev 27:401-411.

Bernácer J, Prensa L, Giménez-Amaya JM (2007) Cholinergic interneurons are differentially distributed in the human striatum. PLoS One 2:e1174.

Bulfone A, Puelles L, Porteus MH, Frohman MA, Martin GR, Rubenstein JL (1993) Spatially restricted expression of Dlx-1, Dlx-2 (Tes-1), Gbx-2, and Wnt- 3 in the embryonic day 12.5 mouse forebrain defines potential transverse and longitudinal segmental boundaries. J Neurosci 13:3155-3172.

Chen L, Guo Q, Li JY (2009) Transcription factor Gbx2 acts cellnonautonomously to regulate the formation of lineage-restriction boundaries of the thalamus. Development 136:1317-1326.

Cobos I, Borello U, Rubenstein JL (2007) Dlx transcription factors promote migration through repression of axon and dendrite growth. Neuron 54:873-888.
Elshatory Y, Gan L (2008) The LIM-homeobox gene Islet-1 is required for the development of restricted forebrain cholinergic neurons. J Neurosci 28:3291-3297.

Fagan AM, Garber M, Barbacid M, Silos-Santiago I, Holtzman DM (1997) A role for TrkA during maturation of striatal and basal forebrain cholinergic neurons in vivo. J Neurosci 17:7644-7654.

Fragkouli A, Hearn C, Errington M, Cooke S, Grigoriou M, Bliss T, Stylianopoulou F, Pachnis V (2005) Loss of forebrain cholinergic neurons and impairment in spatial learning and memory in LHX7-deficient mice. Eur J Neurosci 21:2923-2938.

Furusho M, Ono K, Takebayashi H, Masahira N, Kagawa T, Ikeda K, Ikenaka $\mathrm{K}$ (2006) Involvement of the Olig2 transcription factor in cholinergic neuron development of the basal forebrain. Dev Biol 293:348-357.

Gerfen CR (1992) The neostriatal mosaic: multiple levels of compartmental organization. Trends Neurosci 15:133-139.

Gould E, Woolf NJ, Butcher LL (1991) Postnatal development of cholinergic neurons in the rat: I. Forebrain. Brain Res Bull 27:767-789.

Guo Q, Li JY (2007) Distinct functions of the major Fgf8 spliceform, Fgf8b, before and during mouse gastrulation. Development 134:2251-2260.

Hefti F (1986) Nerve growth factor promotes survival of septal cholinergic neurons after fimbrial transections. J Neurosci 6:2155-2162.

Hevner RF, Miyashita-Lin E, Rubenstein JL (2002) Cortical and thalamic axon pathfinding defects in Tbr1, Gbx2, and Pax6 mutant mice: evidence that cortical and thalamic axons interact and guide each other. J Comp Neurol 447:8-17.

Howell BW, Hawkes R, Soriano P, Cooper JA (1997) Neuronal position in the developing brain is regulated by mouse disabled-1. Nature 389:733-737.

Joyner AL, Zervas M (2006) Genetic inducible fate mapping in mouse: establishing genetic lineages and defining genetic neuroanatomy in the nervous system. Dev Dyn 235:2376-2385.

Kaneko S, Hikida T, Watanabe D, Ichinose H, Nagatsu T, Kreitman RJ, Pastan I, Nakanishi S (2000) Synaptic integration mediated by striatal cholinergic interneurons in basal ganglia function. Science 289:633-637.

Li JY, Joyner AL (2001) Otx2 and Gbx2 are required for refinement and not induction of mid-hindbrain gene expression. Development 128: 4979-4991.

Li JY, Lao Z, Joyner AL (2002) Changing requirements for Gbx2 in development of the cerebellum and maintenance of the mid/hindbrain organizer. Neuron 36:31-43.

Li Y, Holtzman DM, Kromer LF, Kaplan DR, Chua-Couzens J, Clary DO, Knüsel B, Mobley WC (1995) Regulation of TrkA and ChAT expression in developing rat basal forebrain: evidence that both exogenous and endogenous NGF regulate differentiation of cholinergic neurons. J Neurosci $15: 2888-2905$

Liodis P, Denaxa M, Grigoriou M, Akufo-Addo C, Yanagawa Y, Pachnis V (2007) Lhx6 activity is required for the normal migration and specification of cortical interneuron subtypes. J Neurosci 27:3078-3089.

Lucidi-Phillipi CA, Clary DO, Reichardt LF, Gage FH (1996) TrkA activation is sufficient to rescue axotomized cholinergic neurons. Neuron $16: 653-663$.

Madisen L, Zwingman TA, Sunkin SM, Oh SW, Zariwala HA, Gu H, Ng LL, Palmiter RD, Hawrylycz MJ, Jones AR, Lein ES, Zeng H (2009) A robust and high-throughput Cre reporting and characterization system for the whole mouse brain. Nat Neurosci 13:133-140.

Marín O, Rubenstein JL (2001) A long, remarkable journey: tangential migration in the telencephalon. Nat Rev Neurosci 2:780-790.

Marín O, Anderson SA, Rubenstein JL (2000) Origin and molecular specification of striatal interneurons. J Neurosci 20:6063-6076.

Mesulam MM, Mufson EJ, Wainer BH, Levey AI (1983) Central cholinergic pathways in the rat: an overview based on an alternative nomenclature (Ch1-Ch6). Neuroscience 10:1185-1201.

Miyashita-Lin EM, Hevner R, Wassarman KM, Martinez S, Rubenstein JL (1999) Early neocortical regionalization in the absence of thalamic innervation. Science 285:906-909.

Mobley WC, Woo JE, Edwards RH, Riopelle RJ, Longo FM, Weskamp G, Otten U, Valletta JS, Johnston MV (1989) Developmental regulation of nerve growth factor and its receptor in the rat caudate-putamen. Neuron 3:655-664.

Mori T, Yuxing Z, Takaki H, Takeuchi M, Iseki K, Hagino S, Kitanaka J, Takemura M, Misawa H, Ikawa M, Okabe M, Wanaka A (2004) The 
LIM homeobox gene, L3/Lhx8, is necessary for proper development of basal forebrain cholinergic neurons. Eur J Neurosci 19:3129-3141.

Nagy A, Gertsenstein, M., Vintersten, K., and Behringer, R. (2003) Manipulating the mouse embryo, Ed 3. Cold Spring Harbor, NY: Cold Spring Harbor Laboratory.

Olsson M, Björklund A, Campbell K (1998) Early specification of striatal projection neurons and interneuronal subtypes in the lateral and medial ganglionic eminence. Neuroscience 84:867-876.

Paxinos G, Franklin KBJ (2004) The mouse brain in stereotaxic coordinates, Compact Ed 2. Amsterdam, Boston: Elsevier Academic.

Phelps PE, Brady DR, Vaughn JE (1989) The generation and differentiation of cholinergic neurons in rat caudate-putamen. Brain Res Dev Brain Res 46:47-60.

Pisani A, Bernardi G, Ding J, Surmeier DJ (2007) Re-emergence of striatal cholinergic interneurons in movement disorders. Trends Neurosci 30:545-553.

Rhinn M, Lun K, Amores A, Yan YL, Postlethwait JH, Brand M (2003) Cloning, expression and relationship of zebrafish gbx1 and gbx2 genes to Fgf signaling. Mech Dev 120:919-936.

Rhinn M, Lun K, Werner M, Simeone A, Brand M (2004) Isolation and expression of the homeobox gene Gbxl during mouse development. Dev Dyn 229:334-339.

Semba K, Fibiger HC (1988) Time of origin of cholinergic neurons in the rat basal forebrain. J Comp Neurol 269:87-95.

Smythies J (2005) Section I. The cholinergic system. Int Rev Neurobiol 64:1-122.
Soriano P (1999) Generalized lacZ expression with the ROSA26 Cre reporter strain. Nat Genet 21:70-71.

Srinivas S, Watanabe T, Lin CS, William CM, Tanabe Y, Jessell TM, Costantini F (2001) Cre reporter strains produced by targeted insertion of EYFP and ECFP into the ROSA26 locus. BMC Dev Biol 1:4.

Sunmonu NA, Chen L, Li JY (2009) Misexpression of Gbx2 throughout the mesencephalon by a conditional gain-of-function transgene leads to deletion of the midbrain and cerebellum in mice. Genesis 47:667-673.

Sussel L, Marin O, Kimura S, Rubenstein JL (1999) Loss of Nkx2.1 homeobox gene function results in a ventral to dorsal molecular respecification within the basal telencephalon: evidence for a transformation of the pallidum into the striatum. Development 126:3359-3370.

Wassarman KM, Lewandoski M, Campbell K, Joyner AL, Rubenstein JL, Martinez S, Martin GR (1997) Specification of the anterior hindbrain and establishment of a normal mid/hindbrain organizer is dependent on Gbx2 gene function. Development 124:2923-2934.

Waters ST, Wilson CP, Lewandoski M (2003) Cloning and embryonic expression analysis of the mouse Gbxl gene. Gene Expr Patterns 3:313-317.

Wonders CP, Anderson SA (2006) The origin and specification of cortical interneurons. Nat Rev Neurosci 7:687-696.

Xu Q, Tam M, Anderson SA (2008) Fate mapping Nkx2.1-lineage cells in the mouse telencephalon. J Comp Neurol 506:16-29.

Zhao Y, Marín O, Hermesz E, Powell A, Flames N, Palkovits M, Rubenstein JL, Westphal H (2003) The LIM-homeobox gene Lhx8 is required for the development of many cholinergic neurons in the mouse forebrain. Proc Natl Acad Sci U S A 100:9005-9010. 